\title{
AVALIAÇÃO QUALI-QUANTITATIVA DA ARBORIZAÇÃO URBANA NA BACIA HIDROGRÁFICA CÓRREGO DO SAPATEIRO, SÃO PAULO - SP
}

\author{
Quantitative and qualitative valuation of urban forest in a watershed Córrego do \\ Sapateiro, São Paulo - SP
}

Renata Fragoso Potenza, Jefferson Lordello Polizel, Demóstenes Ferreira da Silva Filho

Universidade de São Paulo - Departamento de Ciências Florestais, Escola Superior de

Agricultura "Luiz de Queiroz", SP, Brasil

\section{RESUMO}

A vegetação presente nos ambientes urbanos pode trazer inúmeras contribuições ecológicas, econômicas e sociais. A presente pesquisa objetivou avaliar quali-quantitativamente a arborização na bacia do Córrego do Sapateiro, na cidade de São Paulo (SP). Com isso, foram inventariados todos os indivíduos arbustivos e arbóreos e coletaram-se características físicas, biológicas e fitossanitárias. Foram encontrados 532 indivíduos arbóreos, distribuídos em 54 espécies, pertencentes a 22 famílias. Observou-se a predominância de espécies nativas e a maioria das árvores apresentam um bom estado de conservação (67\%). Avaliou-se também a necessidade de algumas ações para melhoria da qualidade da arborização urbana, sendo alguns exemplos poda de limpeza, ampliação de canteiro, adubação, remoção da vegetação interferente, entre outros.

Palavras-chave: arborização urbana, planejamento urbano, espécies arbóreas.

\section{ABSTRACT}

This vegetation in urban environments can cause numerous ecological, economic and social contributions. This research aimed to valuate qualitative and quantitatively urban forest in a watershed Córrego do Sapateiro the city of São Paulo (SP). Thus, were surveyed every shrub and tree individuals and were collected physical, biological and plant health. We found 532 individual trees, over 54 species belonging to 22 families. There was a predominance of native species and most of the trees have a favorable conservation status (67\%). Was also evaluated the need for some actions to improve the quality of urban trees, some examples pruning of construction magnification, fertilizer, removal of interfering vegetation, among others.

Keywords: urban forestry, urban planning, tree species. 


\section{INTRODUÇÃO}

A urbanização está com um ritmo intenso e acelerado de crescimento e interfere negativamente em algumas questões ambientais. $\mathrm{O}$ crescimento urbano intenso e sem planejamento pode provocar impactos ambientais que modificam as condições naturais de determinada região (SILVA, 2011). Com isso, deve-se encontrar um equilíbrio entre o natural e o artificial, respeitando-se de forma harmoniosa e garantindo a existência do todo.

Para haver um estudo e um planejamento ambiental visando o equilíbrio é importante o conhecimento do local onde será realizado. Uma bacia hidrográfica é composta por áreas que são drenadas por rios principais e seus afluentes. Segundo Tucci e Silveira (2001) ela é definida pela topografia de superfície, contribuindo para o escoamento superficial e infiltração da água no local.

Laera (2004) diz que a arborização existente nas áreas urbanas contribui decisivamente para a criação de zonas de amortecimento e ajuda no conforto ambiental, sendo de elevada importância para a qualidade de vida das populações. Segundo Wolf (2004) os produtos das florestas urbanas geram benefícios intangíveis sendo consideradas como riquezas das populações.

A avaliação da arborização urbana pode-se dar através do inventário arbóreo. Este tem a finalidade de conhecer o patrimônio arbustivo e arbóreo de uma cidade e com isso, facilitar o planejamento e manejo da arborização do local (MELO et. al, 2007).

Os levantamentos quantitativos promovem o conhecimento da quantidade de indivíduos arbóreos presentes na área analisada, além de demonstrar a riqueza local. Essas informações viabilizam um melhor monitoramento e um manejo adequado (SOUZA; BUENO, 2000).

O objetivo desta pesquisa foi analisar a situação atual da arborização urbana no córrego da bacia do Sapateiro - São Paulo/SP, levando em consideração aspectos quantitativos e qualitativos com a finalidade de fornecer resultados sobre a qualidade ambiental desta área.

\section{MATERIAL E MÉTODOS}

O presente trabalho foi realizado na cidade de São Paulo, capital do Estado de São Paulo. Segundo o censo do IBGE (2014) a cidade conta com uma população de aproximadamente 11,9 milhões de habitantes. É considerada a maior cidade do Hemisfério Sul, possui uma área de quase $1.521,1 \mathrm{~km}^{2}$ e uma densidade populacional de aproximadamente $7.400 \mathrm{hab} . / \mathrm{km}^{2}$ (IBGE, 2014).

[removidas 3 frases].

A cidade de São Paulo está localizada no Planalto Atlântico do Sudeste do Brasil com altitudes variantes entre 720 e 850 metros, e próxima ao trópico de Capricórnio. O clima de São Paulo é dividido em cinco unidades, sendo o da região de estudo definido como Clima Tropical Úmido de Altitude do Planalto Atlântico. Possui uma precipitação média anual variante entre 1250 a $1450 \mathrm{~mm}$ e suas temperaturas são mais baixas no mês de julho e mais altas em fevereiro, apresentando uma média anual em torno de $19,3^{\circ} \mathrm{C}$ (TARIFA; ARMANI, 2000).

Dentre as inúmeras bacias hidrográficas existentes na cidade de São Paulo, a bacia do Córrego do Sapateiro é a área escolhida para o presente estudo (figura 1). Essa 
bacia possui uma área de 9,70 km² e está localizada nos bairros de Moema, Itaim Bibi, Jardim Paulista e Vila Mariana e também engloba o Parque Ibirapuera (TOSETTI, 2012). Além disso, apresenta coordenadas $23^{\circ} 56^{\prime}$ de latitude e $46^{\circ} 64^{\prime}$ de longitude (coordenadas da primeira árvore inventariada).

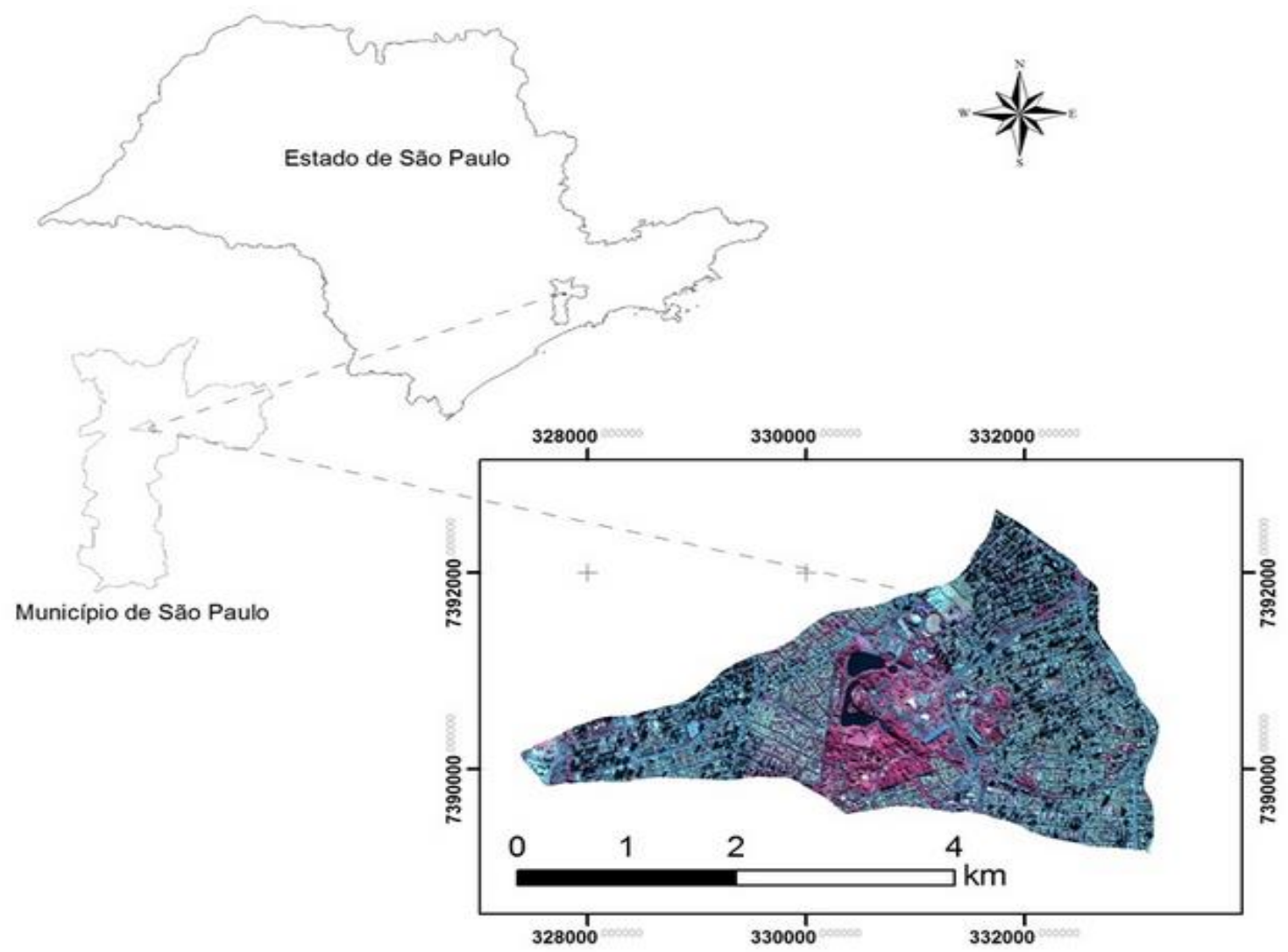

Figura 1 - Localização da bacia do Córrego do Sapateiro, cidade de São Paulo.

O inventário arbóreo foi realizado nos meses de abril, maio e junho de 2013. Para seleção das quadras a serem amostradas foi utilizado o método de amostragem aleatória.

O córrego do Sapateiro apresenta um total de 393 quarteirões (sendo considerados os quarteirões inteiros ou que apresentam mais que $50 \%$ de sua área na bacia) e, para o inventário, foram amostrados 24 quarteirões. Esses blocos foram numerados e selecionados por meio de sorteio.

Em campo, foram tiradas fotos de todas as árvores presentes nos quarteirões inventariados, sempre com a presença da baliza (figura 2), a qual possui um metro de comprimento e permite através do software livre UTHSCSA Image Tool obter informações dendrométricas dos indivíduos analisados como altura geral, diâmetro da copa, diâmetro a altura do peito (DAP), entre outros. Esses dados não serão analisados nesta pesquisa, porém poderá servir de base para estudos posteriores.

A identificação dos indivíduos foi feita em campo, mas quando não possível, foram feitas fotos com detalhes de ramos, flores e frutos para auxiliarem na posterior identificação. 


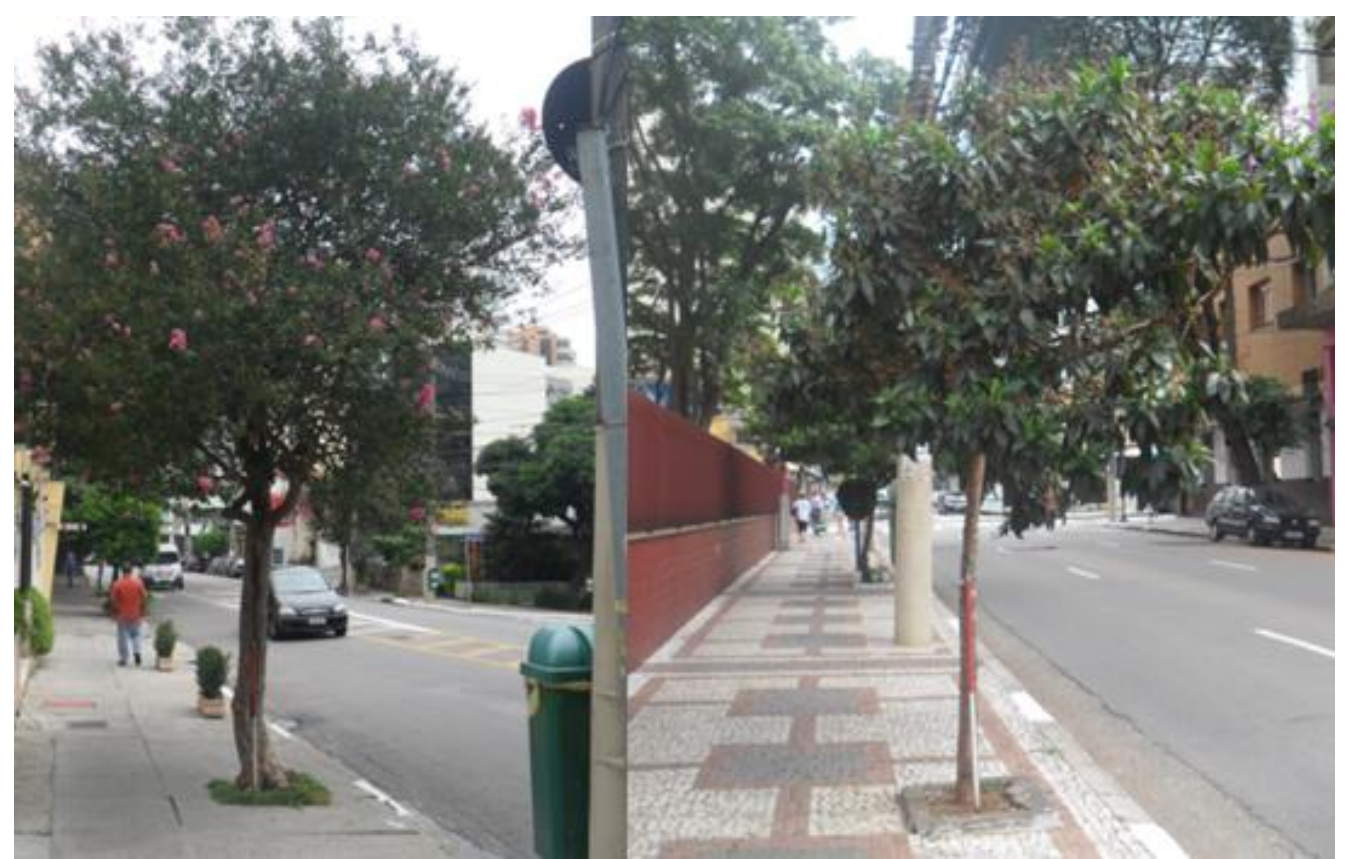

Figura 2 - Árvores inventariadas com a presença da baliza, no bairro Vila Mariana São Paulo/SP.

Além das fotos tiradas, a equipe de campo possui uma planilha para coleta de informações físicas e biológicas dos indivíduos inventariados como: estado geral dos indivíduos, aspectos fitossanitários (presença de pragas, doenças e fungos) e ações recomendadas. Para realização da análise do estado geraldas árvores, tomou-se como base o trabalho de Silva Filho et. al (2002).

Os dados e informações coletados no inventário foram armazenados em um banco de dados no programa Microsoft Acesss. A nomenclatura científica seguiu as normas propostas pelo APG II (AngiospermPhylogenyGroup II) proposto por Souza e Lorenzi (2007). Em relação à distribuição fitogeográfica, origem e grafia adotou-se o banco de dados Lista de espécies da Flora do Brasil (FORZZA et. al, 2010).

\section{RESULTADOS E DISCUSSÃO}

No inventário, foram encontrados 532 árvores e arbustos distribuídos pelas vias públicas delimitadas pela bacia do Córrego do Sapateiro (tabela 1). Estes indivíduos estão distribuídos em 54 espécies, pertencentes a 22 famílias. As espécies que apresentaram maior incidência foram: Largestroemia indica $(14,5 \%)$, Poincianella pluviosa (12,4\%), Ligustrumlucidum (10,5\%), Tipuanatipu (8,5\%) e Bauhiniaforficata (6,2\%). Uma porcentagem de $1,7 \%$ dos indivíduos não pode ser identificada. 
Tabela 1-Relação das espécies arbóreas encontradas na arborização urbana da bacia do Córrego do Sapateiro (SP).

\begin{tabular}{|c|c|c|c|c|c|}
\hline Família & Espécie & Nome Popular & Origem & $\begin{array}{l}\text { Número de } \\
\text { indivíduos }\end{array}$ & $\begin{array}{c}\text { Frequê } \\
\text { ncia }\end{array}$ \\
\hline $\begin{array}{l}\text { Anacardiace } \\
\text { ae }\end{array}$ & Mangifera indica L. & Mangueira & nativa & 4 & 0.8 \\
\hline $\begin{array}{l}\text { Anacardiace } \\
\text { ae }\end{array}$ & Schinusmolle L. & Aroeira-salsa & nativa & 2 & 0.4 \\
\hline $\begin{array}{l}\text { Anacardiace } \\
\text { ae }\end{array}$ & SchinusterebinthifoliusRaddi & $\begin{array}{l}\text { Aroeira- } \\
\text { pimenteira }\end{array}$ & nativa & 1 & 0.2 \\
\hline $\begin{array}{l}\text { Apocynacea } \\
\mathrm{e}\end{array}$ & Neriumoleander L. & Espirradeira & exótica & 4 & 0.8 \\
\hline $\begin{array}{l}\text { Apocynacea } \\
\mathrm{e}\end{array}$ & Plumeria L. & Jasmim-manga & exótica & 2 & 0.4 \\
\hline Araliaceae & ScheffleraJ.R.Forst. \& G. Forst. & Brassaia & nativa & 2 & 0.4 \\
\hline $\begin{array}{l}\text { Bignoneacea } \\
\text { e }\end{array}$ & $\begin{array}{c}\text { Tabebuia roseoalba (Ridl.) } \\
\text { Sandwith }\end{array}$ & Ipê-branco & nativa & 26 & 4.9 \\
\hline $\begin{array}{l}\text { Bignoneacea } \\
\text { e }\end{array}$ & JacarandamimosifoliaD. Don & $\begin{array}{l}\text { Jacarandá- } \\
\text { mimoso }\end{array}$ & exótica & 17 & 3.2 \\
\hline $\begin{array}{l}\text { Bignoneacea } \\
\text { e }\end{array}$ & $\begin{array}{c}\text { Tabebuia impetiginosa (Mart. ex } \\
\text { DC.) Standl }\end{array}$ & Ipê-rosa & nativa & 12 & 2.3 \\
\hline $\begin{array}{l}\text { Bignoneacea } \\
\text { e }\end{array}$ & $\begin{array}{l}\text { Tabebuia chrysotricha (Mart. ex } \\
\text { DC.) Standl. }\end{array}$ & $\begin{array}{l}\text { Ipê-amarelo-do- } \\
\text { cerrado }\end{array}$ & nativa & 10 & 1.9 \\
\hline $\begin{array}{l}\text { Bignoneacea } \\
\text { e }\end{array}$ & $\begin{array}{c}\text { Tabebuia heptaphylla (Vell.) } \\
\text { Toledo }\end{array}$ & Ipê-roxo & nativa & 10 & 1.9 \\
\hline $\begin{array}{l}\text { Bignoneacea } \\
\text { e }\end{array}$ & Spathodeacampanulata P. Beauv. & Espatodea & exótica & 3 & 0.6 \\
\hline $\begin{array}{l}\text { Bignoneacea } \\
\text { e }\end{array}$ & $\begin{array}{c}\text { Tabebuia avellanedae Lorentz } \\
\text { exGriseb }\end{array}$ & $\begin{array}{l}\text { Ipê-rosa- } \\
\text { americano }\end{array}$ & nativa & 3 & 0.6 \\
\hline $\begin{array}{l}\text { Bignoneacea } \\
\text { e }\end{array}$ & Tecomastans (L.) Juss. exKunth & Ipê-de-jardim & exótica & 1 & 0.2 \\
\hline Caricaceae & Caricapapaya L. & Mamoeiro & exótica & 1 & 0.2 \\
\hline $\begin{array}{l}\text { Chrysobalan } \\
\text { aceae }\end{array}$ & Licania tomentosa (Benth.) Fritsch & Oiti & nativa & 9 & 1.7 \\
\hline $\begin{array}{l}\text { Combretace } \\
\text { ae }\end{array}$ & Terminaliacatappa L. & Chapéu-de-sol & $\begin{array}{l}\text { subespont } \\
\text { ânea }\end{array}$ & 1 & 0.2 \\
\hline Fabaceae & $\begin{array}{c}\text { Poincianella pluviosa (DC.) } \\
\text { L.P.Queiroz }\end{array}$ & Sibipiruna & nativa & 66 & 12.4 \\
\hline Fabaceae & Tipuanatipu (Benth.) Kuntze & Tipuana & $\begin{array}{l}\text { subespont } \\
\text { ânea }\end{array}$ & 45 & 8.5 \\
\hline Fabaceae & Bauhiniaforficata Link & Pata-de-vaca & nativa & 33 & 6.2 \\
\hline Fabaceae & Delonix regia (BojerexHook.) Raf. & Flamboyant & $\begin{array}{l}\text { subespont } \\
\text { ânea }\end{array}$ & 16 & 3.0 \\
\hline Fabaceae & MachaeriumscleroxylonTul. & Pau-ferro & nativa & 5 & 0.9 \\
\hline Fabaceae & CaesalpiniaechinataLam. & Pau-Brasil & nativa & 5 & 0.9 \\
\hline Fabaceae & CalliandraBenth. & Esponjinha & nativa & 3 & 0.6 \\
\hline Fabaceae & $\begin{array}{l}\text { Piptadeniagonoacantha (Mart.) } \\
\text { J.F.Macr. }\end{array}$ & Pau-jacaré & nativa & 2 & 0.4 \\
\hline Fabaceae & Cassia L. & Cassia & nativa & 1 & 0.2 \\
\hline
\end{tabular}




\begin{tabular}{|c|c|c|c|c|c|}
\hline Fabaceae & Cassia leptophyllaVogel & $\begin{array}{c}\text { Falso- } \\
\text { barbatimão }\end{array}$ & nativa & 1 & 0.2 \\
\hline Fabaceae & Caesalpiniapulcherrima (L.) Sw. & $\begin{array}{l}\text { Flamboyant-de- } \\
\text { jardim }\end{array}$ & $\begin{array}{l}\text { subespont } \\
\text { ânea }\end{array}$ & 1 & 0.2 \\
\hline Fabaceae & HolocalixbalansaeMicheli & $\begin{array}{l}\text { Alecrim-de- } \\
\text { campinas }\end{array}$ & nativa & 5 & 0.9 \\
\hline Lauraceae & Persea major (Meisn.) L.E.Kopp & Abacateiro & nativa & 2 & 0.4 \\
\hline Lauraceae & $\begin{array}{c}\text { Nectandramegapotamica (Spreng.) } \\
\text { Mez }\end{array}$ & Canelinha & nativa & 2 & 0.4 \\
\hline Lythraceae & LafoensiaglyptocarpaKoehne & Mirindiba & nativa & 12 & 2.3 \\
\hline Lythraceae & Lagerstroemia indica (L.) Pers. & Resedá & nativa & 77 & 14.5 \\
\hline $\begin{array}{l}\text { Magnoliacea } \\
\mathrm{e}\end{array}$ & Magnoliachampaca L. & $\begin{array}{l}\text { Magnólia- } \\
\text { amarela }\end{array}$ & exótica & 6 & 1.1 \\
\hline Malvaceae & Hibiscus L. & Hibisco & nativa & 5 & 0.9 \\
\hline Malvaceae & Ceibaspeciosa (A.St.-Hil.) Ravenna & Paineira & nativa & 2 & 0.4 \\
\hline Malvaceae & Taliparititiliaceum (L.) Fryxell & $\begin{array}{l}\text { Algodão-da- } \\
\text { praia }\end{array}$ & exótica & 1 & 0.2 \\
\hline $\begin{array}{l}\text { Melastomat } \\
\text { aceae }\end{array}$ & $\begin{array}{l}\text { Tibouchina granulosa (Desr.) } \\
\text { Cogn. }\end{array}$ & Quaresmeira & nativa & 27 & 5.1 \\
\hline $\begin{array}{l}\text { Melastomat } \\
\text { aceae }\end{array}$ & Tibouchinapulchra Cogn. & $\begin{array}{l}\text { Manacá-da- } \\
\text { serra }\end{array}$ & nativa & 1 & 0.2 \\
\hline Moraceae & Ficusbenjamina L. & $\begin{array}{c}\text { Figueira- } \\
\text { benjamina }\end{array}$ & exótica & 13 & 2.4 \\
\hline Moraceae & Morus nigraL. & Amora-preta & exótica & 5 & 0.9 \\
\hline Moraceae & FicusguaraniticaChodat & Figueira-branca & nativa & 2 & 0.4 \\
\hline Myrtaceae & Eugenia uniflora L. & Pitangueira & nativa & 2 & 0.4 \\
\hline Myrtaceae & $\begin{array}{l}\text { Callistemonviminalis G. Don } \\
\text { exLoud }\end{array}$ & $\begin{array}{l}\text { Escovinha-de- } \\
\text { garrafa }\end{array}$ & exótica & 1 & 0.2 \\
\hline Myrtaceae & Psidiumguajava L. & Goiabeira & $\begin{array}{l}\text { subespont } \\
\text { ânea }\end{array}$ & 1 & 0.2 \\
\hline Myrtaceae & Syzygiumcumini (L.) Skeels & Jambolão & $\begin{array}{l}\text { subespont } \\
\text { ânea }\end{array}$ & 1 & 0.2 \\
\hline Oleaceae & Ligustrumlucidum W.T. Aiton & Alfeneiro & $\begin{array}{l}\text { subespont } \\
\text { ânea }\end{array}$ & 56 & 10.5 \\
\hline $\begin{array}{l}\text { Phytolaccac } \\
\text { eae }\end{array}$ & Phytolacca dioica $\mathrm{L}$. & Umbú & nativa & 1 & 0.2 \\
\hline $\begin{array}{l}\text { Polygonacea } \\
\text { e }\end{array}$ & Triplaris L. & Pau-formiga & nativa & 1 & 0.2 \\
\hline Rhamnaceae & HoveniadulcisThunb. & Uva-do-Japão & exótica & 1 & 0.2 \\
\hline Rubiaceae & $\begin{array}{l}\text { Calycophyllumspruceanum } \\
\text { (Benth.) K. Schum. }\end{array}$ & Pau-mulato & nativa & 2 & 0.4 \\
\hline Rutaceae & Murrayapaniculata (L.) Jack & Falsa murta & exótica & 6 & 1.1 \\
\hline Rutaceae & EsenbeckiariedelianaEngl. & Guatambu & nativa & 2 & 0.4 \\
\hline Sapotaceae & Chrysophyllumarenarium Allemão & Ameixeira & nativa & 3 & 0.6 \\
\hline - & - & $\begin{array}{c}\text { Não } \\
\text { identificado }\end{array}$ & - & 9 & 1.7 \\
\hline
\end{tabular}


As famílias mais representativas neste trabalho foram Fabaceae (35\%), Lythraceae (17\%), Bignonaceae (15,7\%) e Oleaceae $(10,7 \%)$, sendo as demais famílias representadas por apenas $21,6 \%$.

A presença de uma grande quantidade de uma única espécie ou um grupo de espécies pode causar um desequilíbrio ecológico na região, como auxiliar na propagação de pragas e doenças dos indivíduos presentes nos centros urbanos (JÚNIOR et. al, 2008).Um índice de diversidade de espécies pode ser utilizado para tentar garantir a sanidade das árvores, dessa forma, recomenda-se não exceder mais que $10 \%$ da mesma espécie e 30\% da mesma família botânica (SANTAMOUR JÚNIOR, 1990).

A família Fabaceae (35\%) e as espécies Resedá (14,5\%), Sibipiruna (12,4\%) e Alfeneiro (10,5\%) estão acima dos limites recomendados por Santamour Júnior (1990), tal situação pode afetar a sanidade dos indivíduos arbóreos locais.

Na cidade de Garça foi encontrada uma situação semelhante à deste trabalho. A espécie mais abundante é a Largestroemia indica e a família é a Fabaceae (NUNES et. al, 2013). Porém em Sorocaba a situação já se torna diferente, a espécie mais frequente é a Poincianella pluviosa.

Outro fator que pode afetar a diversidade e sobrevivência das árvores nos ambientes urbanos é a presença de espécies exóticas invasoras. Elas posicionam-se em segundo lugar na lista das causas de extinções das espécies no mundo (BLUM et. al, 2008). A vegetação encontrada na bacia do Córrego do Sapateiro é representada principalmente por espécies nativas $(65,2 \%)$, predominância recomendada para arborização de vias públicas. Apesar de ideal, a dominância de espécies nativas é incomum nas cidades brasileiras e em inúmeros trabalhos pode-se ver o predomínio das espécies exóticas como nos casos de Garça - SP (NUNES et. al, 2013) com 62,6\%, de Franca - SP (SILVA et. al, 2008) com 68,5\% e de Taubaté - SP (MINHOTO et. al, 2009) com $57,5 \%$.

A avaliação qualitativa das árvores pode ser observada através da análise das condições gerais dos indivíduos, as quais são classificadas em ótimo, bom, regular e péssimo e baseia-se no trabalho de Silva Filho et. al (2002). Para realizar esta análise, observa-se as condições de vigor e saúde, presença de insetos, doenças ou injúrias e necessidade de manutenção nos indivíduos arbóreos.

A maior parte dos exemplares encontrados está considerada em bom estado(67\%) e apenas 1\% dos indivíduos estão em péssimo estado (figura 3). 


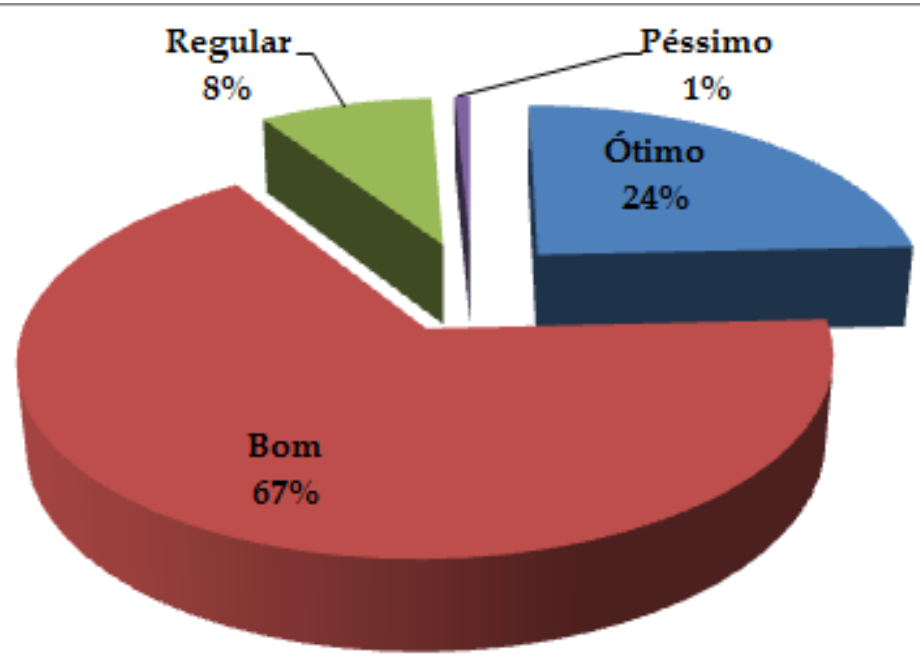

Figura 3 - Estado geral dos indivíduos inventariados na bacia do Córrego do Sapateiro - São Paulo / SP.

A situação apresentada acima é também verdadeira para a cidade de Garça com $87,5 \%$ dos indivíduos sadios e com vigor (NUNES et. al, 2008) e para o bairro de Lauzane Paulista na cidade de São Paulo, que apresenta 85,3\% das árvores inventariadas em bom estado (SOUZA et. al, 2014).

A partir da situação das árvores analisadas fizeram-se recomendações visando à melhoria dos indivíduos e sua permanência no meio em que se encontram. Recomenda-se a realização de poda para $80,3 \%$ dos casos observados assim como ampliação dos canteiros (20,3\%), reparo de danos $(5,1 \%)$, adubação $(5,1 \%)$, remoção da vegetação interferente $(5,1 \%)$ e auxílio na condução $(2,6 \%)$ (figura 4$)$.

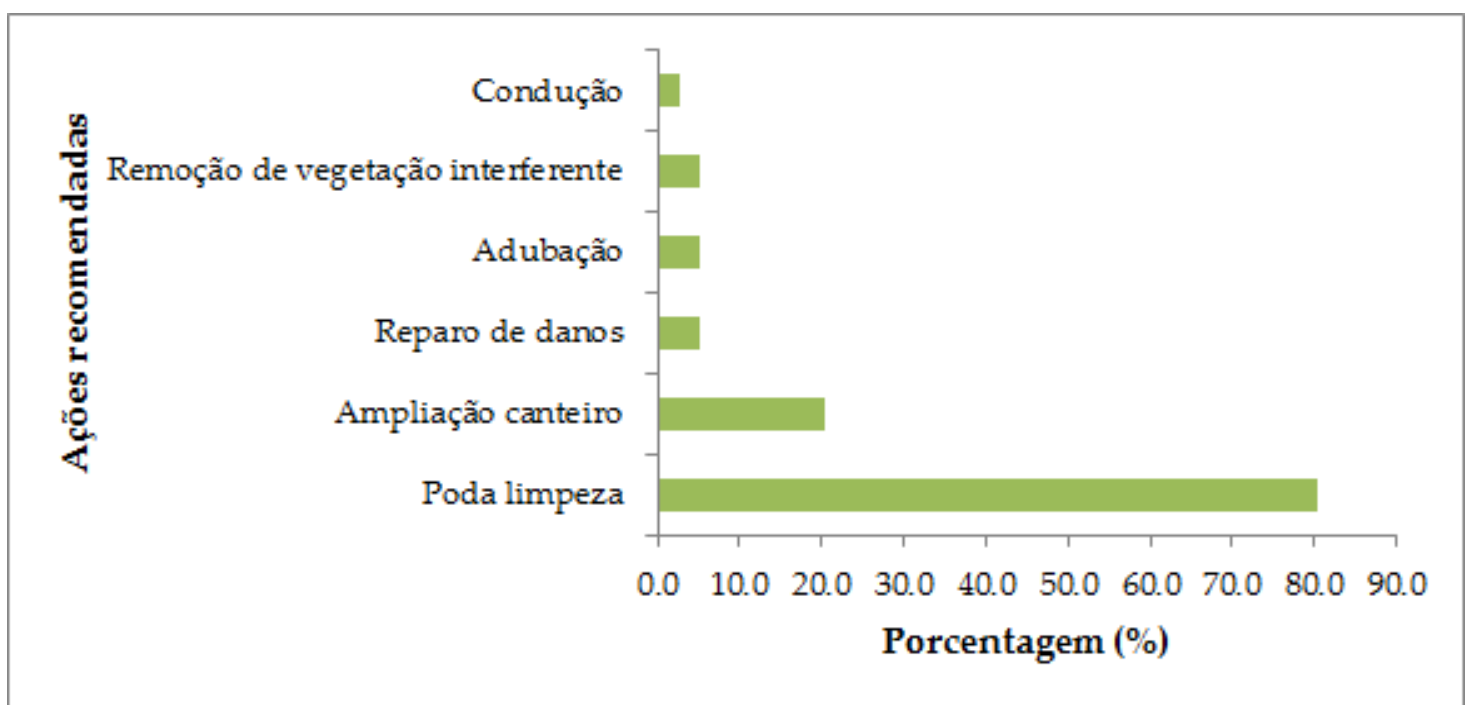

Figura 4 - Ações recomendadas para as árvores inventariadas na bacia do Córrego Sapateiro - São Paulo/SP.

O monitoramento e a realização destas ações de reparo, cuidado e manutenção destes indivíduos proporcionam boa qualidade às pessoas que desfrutam do conforto e benefícios gerados pelas árvores presentes nas vias públicas. 


\section{CONCLUSÕES}

A bacia do Córrego do Sapateiro possui uma grande diversidade de espécies arbóreas, além de apresentar uma boa quantidade de indivíduos nativos. A espécie mais abundante no local é a Largestroemia indica $(14,5 \%)$ e a família mais representativa é Fabaceae (35\%).

As árvores, em sua grande maioria, apresentam um bom estado de conservação, porém alguns indivíduos foram considerados em péssimo estado e necessitam de um monitoramento.Algumas ações precisam ser realizadas para manutenção e melhoria da qualidade da arborização urbana, sendo as principais poda de limpeza e ampliação de canteiro.

\section{REFERÊNCIAS BIBLIOGRÁFICAS}

BLUM, C. T.; BORGO, M.; SAMPAIO, A. C. F. Espécies exóticas invasoras na arborização de vias públicas de Maringá - PR. Revista da Sociedade Brasileira de Arborização Urbana, Piracicaba, v. 3, n. 2, p. 78-97, 2008.

CENTRO DE PESQUISAS METEOROLÓGICAS E CLIMÁTICAS APLICADAS À AGRICULTURA. Disponível em: <http://www.cepagri.unicamp.br/>. Acesso em: 15 dez. 2014.

FORZZA, R.C.; LEITMAN, P.M.; COSTA, A.F.; CARVALHO JR., A.A.; PEIXOTO, A.L.; WALTER, B.M.T.; BICUDO, C.; ZAPPI, D.; COSTA, D.P.; LLERAS, E.; MARTINELLI, G.; LIMA, H.C.; PRADO, J.; STEHMANN, J.R.; BAUMGRATZ, J.F.A.; PIRANI, J.R.; SYLVESTRE, L.; MAIA, L.C.; LOHMANN, L.G.; QUEIROZ, L.P.; SILVEIRA, M.; COELHO, M.N.; MAMEDE, M.C.; BASTOS, M.N.C.; MORIM, M.P.; BARBOSA, M.R.; MENEZES, M.; HOPKINS, M.; SECCO, R.; CAVALCANTI, T.B.; SOUZA, V.C. Introdução. In: Lista de Espécies da Flora do Brasil. Jardim Botânico do Rio de Janeiro. 2010. Disponível em: <http://floradobrasil.jbrj.gov.br/>. Acesso em: 11 mar. 2015.

INSTITUTO BRASILEIRO DE GEOGRAFIA E ESTATÍSTICA. IBGE Cidades. 2014.

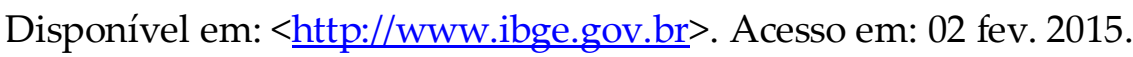

JÚNIOR, F. R.; MELLO, R. R.; CUNHA, T. A.; STANGERLIN, D. M. Análise da arborização urbana em bairros da cidade de Pombal no estado da Paraíba. Revista da Sociedade Brasileira de Arborização Urbana, Piracicaba, v.3, n.4, p.3-19, 2008.

LAERA, L.H.N. Valoração econômica da arborização - A valoração dos serviços ambientais para a eficiência e manutenção do recurso ambiental urbano. 2006. 131p. Dissertação (Mestrado em Ciência Ambiental) - Universidade Federal Fluminense, Niterói, 2006. 
MELO, R.R.; FILHO, J.A.; RODOLFO JÚNIOR, F. Diagnóstico qualitativo e quantitativo da arborização urbana no bairro Bivar Olinto, Patos, Paraíba. Revista da Sociedade Brasileira de Arborização Urbana, v.2, n.1, 2007, p.64-78

MINHOTO, E.S.; MONTEIRO, E.A.; FISCH, S.T.V. Arborização viária na cidade de Taubaté, SP: no centro comercial histórico e um bairro residencial moderno. Revista da Sociedade Brasileira de Arborização Urbana, v. 4, n. 2, p. 82-96, 2009.

NUNES, R.L.; MARMONTEL, C.V.F.; RODRIGUES, J.P.; MELO, A.G.C. Levantamento qualiquantitativo da arborização urbana do bairro ferraropólis na cidade de Garça SP.Revista da Sociedade Brasileira de Arborização Urbana, Piracicaba, v.8, n.1, p. 6574, 2013.

ROSSETTI, A.I.N; PELLEGRINO, P.R.M; TAVARES, A.R. O espaço metropolitano na cidade de São Paulo e sua interface com a Arborização: aspectos da transformação socioeconômica, do sítio físico e da proteção de vegetais de porte arbóreo. Revista da Sociedade Brasileira de Arborização Urbana, Piracicaba, v.4, n.1, p. 21-38, 2009.

SANTAMOUR JUNIOR, F.S. Trees for urban planting: diversity, uniformity, and common sense.In: METRIA CONFERENCE,7., 1990, Lisle. Proceedings...Lisle: 1990. p.57-66.

SILVA FILHO, D.F; PIZZETA, P.U.C; ALMEIDA, J.B.S.A; PIVVETTA, K.F.L; FERRAUDO, A.S. Banco de dados relacional para cadastro, avaliação e manejo da arborização em vias públicas. Revista árvore, Viçosa, v.26, n.5, p. 629-642, 2002.

SILVA, M.D.M.; SILVEIRA, R.P; TEIXEIRA, M.I.J.G. Avaliação da arborização de vias públicas de uma área da região oeste da cidade de Franca/SP. Revista da Sociedade Brasileira de Arborização Urbana, v .3, n. 1, p. 19-35, 2008.

SILVA, R.S; MACHADO, P.J. Inundações Urbanas: O caso da microbacia hidrográfica do córrego do Ipiranga - Juiz de Fora/MG. ANAP, v.7, n.2, 2011.

SOUZA, M.A.L.B.; BUENO, O.C. Planejamento da arborização urbana. In: CONGRESSO BRASILEIRO DE ARBORIZAÇÃO URBANA, 5.;Anais. Rio de Janeiro, 2000.

SOUZA, R. de C.; AGUIAR, O.T. de; SILVA, L.T.A.; SILVA, L.A.; MARRA, R.C. Avaliação quali-quantitativa da arborização na praça Agostinho Nohama, bairro Lauzane Paulista, São Paulo - SP. Revista da Sociedade Brasileira de Arborização Urbana, v .9, n. 1, p. 92-107, 2014.

SOUZA, V. C.; LORENZI, H. Botânica Sistemática: guia ilustrado para identificação das famílias de Angiospermas da flora brasileira, baseado em APG II. 2 ed. Instituto Plantarum, Nova Odessa, 2007. 
TARIFA, J. R.; ARMANI, G. Atlas Ambiental do Município de São Paulo - Fase I: diagnósticos e bases para a definição de políticas públicas para as áreas verdes no município de São Paulo. Unidades Climáticas Urbanas da Cidade de São Paulo. Laboratório de Climatologia. Departamento de Geografia/ Faculdade de Filosofia, Letras e Ciências Humanas - Universidade de São Paulo, 2000. 74 p.

TOSETTI, L.L. Valoração arbórea em bacia hidrográfica urbana. 2012. 82 p. Dissertação (Mestrado em Recursos Florestais) - Escola Superior de Agricultura "Luiz de Queiroz", Universidade de São Paulo, Piracicaba, 2012.

TUCCI, C.E.M; SILVEIRA, A. 2001. Gerenciamento da drenagem urbana. Disponível em:<http://galileu.iph.ufrgs.br/joel/IPH014/Gerdre.pdf>. Acesso em: 05 mar. 2015.

WOLF, K.L. A economia e o valor público das florestas urbanas. Revista de Agricultura Urbana, 2004. Disponível em: $<$ http://www.agriculturaurbana.org.br/RAU/AU13/AU13economics.html $>$. Acesso em: 06mar. 2015. 